\title{
PerCursos
}

\section{Comunidade indígena Fuduwaadunha: vida e convivência na região de Auaris - Terra Indígena Yanomami - Roraima}

\section{Resumo}

O estudo discute o uso do território pela comunidade Fuduwaadunha da região de Auaris, na Terra Indígena Yanomami, em Roraima. Nessa região vive o povo Ye'kuana. Após a década 1960, a região de Auaris sofreu alterações na paisagem e na ocupação territorial com a chegada dos agentes não indígenas, inicialmente a Missão Evangélica da Amazônia (MEVA) e, posteriormente, a Fundação Nacional de Saúde (FUNASA), a Fundação Nacional do Índio (FUNAI) e o Exército Brasileiro (Pelotão Especial de Fronteira-PEF). Esses novos atores levaram a mudanças na forma de uso e ocupação do território para os povos que ali vivem e, nesse contexto, o artigo busca compreender os usos do território na região e os desafios que têm enfrentado diante de um novo contexto. Entre os desafios, estão a gestão do território frente a um crescimento populacional e aumento de comunidades na região, com a abertura de novas áreas para produção agrícola e conflitos pelo uso dos recursos naturais (caça, pesca, extrativismo), bem como as fragilidades nos limites territoriais entre grupos sociais.

Palavras-chave: Terra Indígena Yanomami. Território. Ye'kuana.

\section{Castro Costa da Silva}

Mestre em Geografia pela

Universidade Federal de Roraima

- UFRR. Membro da Associação

do Povo Ye'kuana no Brasil. Brasil

castroyekuana@gmail.com

\section{Maria Bárbara de Magalhães Bethonico}

Doutora em Geografia pela Univ.

Federal Fluminense - UFF.

Professora do curso de Gestão

Territorial Indígena da Univ.

Federal de Roraima - UFRR.

Brasil

maria.bethonico@ufrr.br

\section{Para citar este artigo:}

SILVA, Castro Costa da; BETHONICO, Maria Bárbara de Magalhães. Comunidade indígena Fuduwaadunha: vida e convivência na região de Auaris - Terra Indígena Yanomami - Roraima. PerCursos, Florianópolis, v. 22, n.48, p. 208 - 232, jan./abr. 2021.

DOI: $10.5965 / 1984724622482021208$

http://dx.doi.org/10.5965/1984724622482021208 


\title{
Fuduwaadunha indigenous community: life and coexistence in the Auaris region - Yanomami Indigenous Land - Roraima
}

\begin{abstract}
The study discusses the land use by the Fuduwaadunha community from the Auarís region in the Yanomami Indigenous Land in Roraima. The Ye'kuana people live in this region. After the 1960s, the Auaris region changed its landscape and territorial occupation with the arrival of non-indigenous agents, initially the Evangelical Mission of the Amazon (MEVA) and later the National Health Foundation (FUNASA), the National Indian Foundation (FUNAI), and the Brazilian Army (Special Border Platoon PEF). These new actors have led to changes in how people who live there use and occupy the territory. In this context, the study seeks to understand the land uses in the region and the challenges in this new context. Among the challenges is the land management regarding the population growth and the increasing number of communities in the region, with the establishment of new areas for agricultural production and conflicts over the use of natural resources (hunting, fishing, extractivism), as well as the fragility of the territorial limits between social groups.
\end{abstract}

Keywords: Yanomami Indigenous Land. Territory.

Ye'kuana. 


\section{Introdução}

A região de Auaris está localizada no extremo noroeste da Terra Indígena Yanomami e refere-se à área da bacia hidrográfica do rio de mesmo nome, afluente do rio Uraricoera. Essa região é ocupada tradicionalmente por dois povos: os Ye'kuana e os Sanumã, este último um subgrupo Yanomami. O estudo aqui apresentado contempla o povo Ye’kuana que vive na comunidade Fuduwaadunha, localizada no médio curso do rio Auaris.

Na segunda metade do século $X X$, esses povos presenciaram a intensificação de um processo de intervenção em seus territórios, situação que mesmo com a homologação da terra indígena no ano de 1992, continua presente, na presença do exército ( $5^{\circ}$ Pelotão Especial de Fronteira de Auaris), na Missão Evangélica da Amazônia/MEVA, nas escolas e na Fundação Nacional do Índio/FUNAI. Esses novos elementos no espaço próximo da comunidade Fuduwaadunha levaram a um processo de sedentarização, com a redução de uma movimentação de famílias e novos modos de vida. Atualmente, é possível observar a construção de moradias em locais próximos aos objetos espaciais implantados pelo Estado nas aldeias, situação que tem se tornado o grande motor dessas mudanças.

A sedentarização e formação de novas comunidades trouxe como consequência uma demanda crescente por recursos naturais e sua escassez, como redução da caça, da pesca, de palhas, madeiras e de solos férteis para as roças que agora estão disponíveis em locais cada vez mais distantes das comunidades.

Neste contexto, o artigo apresenta parte dos resultados de uma pesquisa desenvolvida no Programa de Pós-graduação em Geografia da Universidade Federal de Roraima e teve como objetivo compreender as mudanças na vida, produção e convivência dos moradores da comunidade indígena Fuduwaadunha, e descrever aspectos históricos da região, o morar, a produção de alimentos e a interação com os não ndios.

Os Ye'kuana desta comunidade têm como vizinhos os Sanumã e ocupam espaços geográficos próximos há mais de meio século. Atualmente, é um polo de atração para 
moradores de outras comunidades devido à presença de políticas públicas implantadas neste lugar, como a construção da pista de pouso que, na década de 1990, foi ampliada e asfaltada. Além da fixação de novos moradores, também houve um aumento populacional na região de Auaris. Sem a presença do não indígena, a mobilidade das comunidades era frequente e os recursos naturais não sofriam tanta pressão, pois não havia concentração das pessoas.

Importante ressaltar que o artigo é fruto de uma dissertação de mestrado cujo autor é da etnia Ye'kuana e as análises aqui apresentadas partem desse olhar, do pensamento de um Ye'kuana morador de Fuduwaadunha. Foi feito um esforço no sentido de entender as relações de convivência, do desenrolar da vida através das atividades e interações entre a sociedade e a natureza (socionaturais) que ocorrem neste espaço usado, transformado em território.

O território, que recebe o nome de nonodö, na visão Ye'kuana, não é um espaço vazio, mas repleto de espíritos bons ou ruins; é preciso existir o respeito aos lugares como as serras, além do respeito à água, aos animais, às pedras e florestas, uma vez que estão ligados aos seus donos invisíveis que podem prejudicar a saúde de um Ye'kuana e leva-lo à morte. Esse povo recebeu o território do criador do mundo, como mencionado no wätunä (conjunto de conhecimentos tradicionais e simbólicos do povo Ye'kuana que é repassado pelas gerações), garantindo a todos os habitantes da terra um local para viver. Para Silva e Bethonico (2017), esses territórios associados a um povo indígena foram habitados pelos seus ancestrais e estão repletos de referências materiais e imateriais. Os seus limites não coincidem com as fronteiras territoriais impostas pelo Estado sendo, também, território Ye'kuana as áreas localizadas além da fronteira, na Venezuela.

Para compreender o uso do território pelos Ye'kuana foram realizadas entrevistas e oficinas para levantamento de informações e construção de um calendário socionatural, com a análise das atividades produtivas humanas, os recursos naturais a partir do qual se elabora um produto e as técnicas utilizadas de acordo com o meio em que vivem. Com base nessa proposta metodológica, o território engloba a todos e está na base da interação sociedade-natureza, envolvendo os homens, os animais, o ar, o solo, a água, as plantas e tudo o que existe (SARTORELLO, 2011), incluindo os seres invisíveis que 
caracterizam o território para os Ye'kuana.

As atividades demonstradas no calendário socionatural foram espacializadas de forma a indicar os locais de ação e usos diversos no território, os espaços de produção onde praticam a caça, a pesca, a retirada de produtos florestais (madeira e palha) e onde realizam os cultivos, todas as atividades essenciais para a sobrevivência do grupo. Ao apresentar as atividades e sua espacialização, identificamos as fragilidades territoriais entre os Ye'kuana e seus vizinhos, os Sanumã, como indicativos que soluções devem ser pensadas no que se refere à instalação de infraestrutura do Estado e suas consequências, uma vez que influenciam na gestão de territórios e na vida de seus habitantes.

\section{Os indígenas e os novos moradores no território tradicional}

Após a década 1960, a ocupação da região de Auaris, onde está localizada a comunidade Fuduwaadunha (Figura 1), começou a se modificar com a construção da pista de pouso. A partir do objeto construído, a "pista", chegaram novos agentes externos como a Missão Evangélica da Amazônia (MEVA), a Fundação Nacional de Saúde (FUNASA), a Fundação Nacional do Índio (FUNAI) e o $5^{\circ}$ Pelotão Especial de Fronteira (Exército Brasileiro); modifica-se, assim, o modo de ocupação do território pelas comunidades indígenas em Auaris. Após a construção desses objetos fixos, as comunidades começaram a receber novos habitantes, como os indígenas oriundos de outras comunidades distantes, algumas localizadas na Venezuela, que se aproximaram em busca de produtos manufaturados que eram fornecidos por funcionários de órgãos estatais e missionários. O acesso a serviços e bens fez com que a mobilidade que sempre ocorreu diminuísse, como é o caso da comunidade Ye'kuana que se tornou sedentária, e a comunidade vizinha (Sanumã) que passou a ficar próxima à pista de pouso. 
Figura 1 - localização da comunidade Fuduwaadunha - Terra Indígena Yanomami

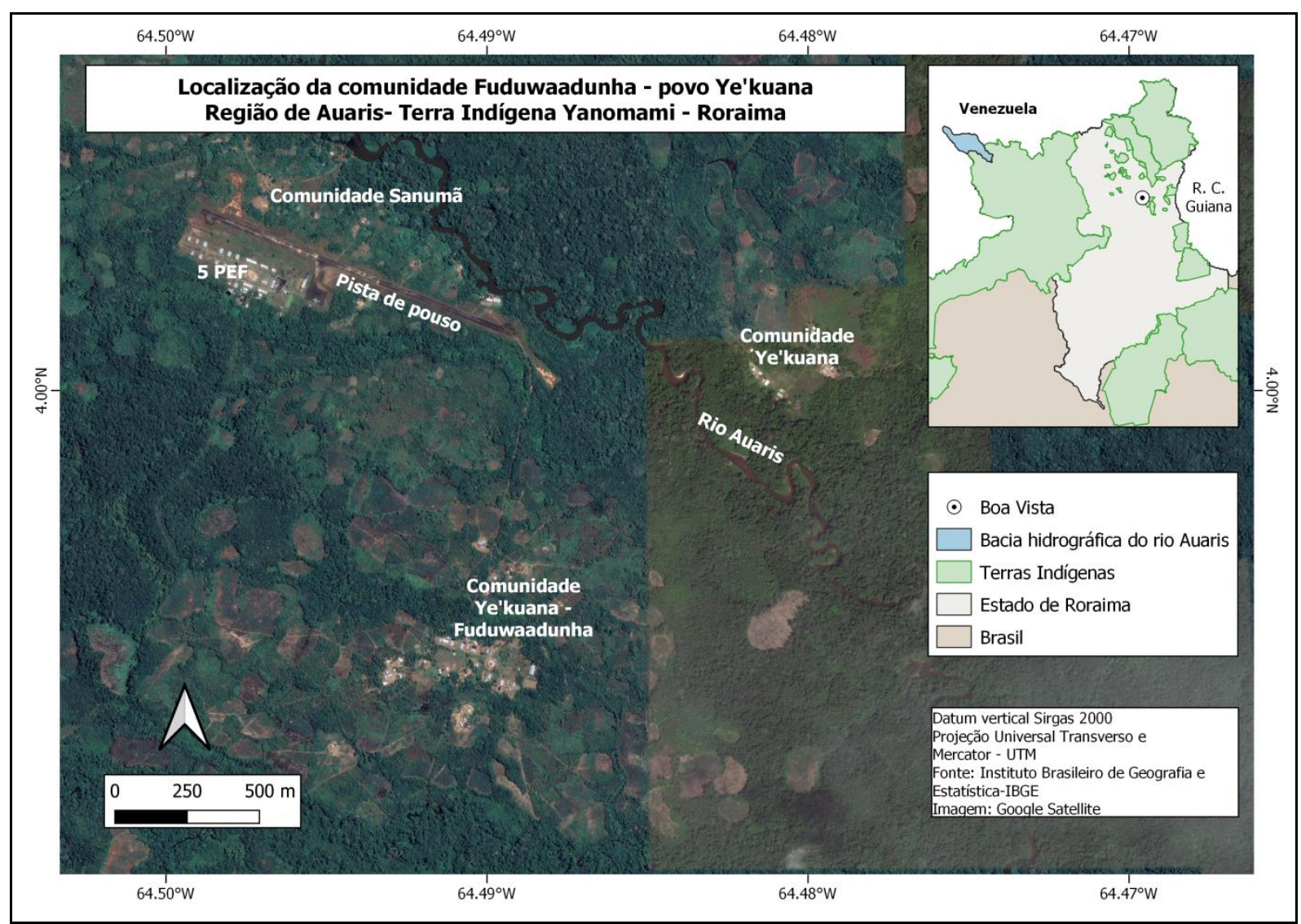

Fonte: Elaborado pelos autores, 2021.

Os Ye'kuana recebem outras denominações como Maiongong e Maquiritare. Falam uma língua pertencente à família linguística caribe e habitam a região das cabeceiras dos rios Auaris, Caura, Cunucunuma, Ventuari e Metakuni em território brasileiro e venezuelano. Compartilham o mesmo espaço geográfico com um subgrupo Yanomami, “os Sanumã”, que se autodenominam Sanuma dïbï (Sanuma "gente”, dïbï é o plural - mais de dois). Setenapi töpö é a forma como eles denominam "os brancos"; chamam aos Ye’kuana de Nabï dïbï, e falam a língua sanumã, uma das quatro línguas conhecidas da família linguística Yanomami (Sanumã, Yanomam, Yanomamï e Yanam). Os Sanumã são originários das serras de Parima, nas cabeceiras do rio Orinoco (Venezuela) e do rio Parima (Brasil), mas, com as brigas internas entre subgrupos Yanomami, ocorreu a divisão e os Sanumã dirigiram-se para o norte, atingindo as terras de povos caribe, como 
os Ye'kuana.

Na convivência entre esses dois povos que habitam a região de Auaris aparecem alguns conflitos e que, por vezes, entram em discussões mais acaloradas. Desde 1960, a comunidade Ye'kuana mudou-se por três vezes em uma distância de menos dois quilômetros devido a um crescimento populacional, situação que atingiu também a comunidade Ashikama dos Sanumã, que tem sua população aumentada a cada ano. Atualmente, as pessoas sofrem com problemas decorrentes da mudança de hábitos, como o fim de mobilidade das comunidades e a escassez dos recursos naturais. No início do século XX, por exemplo, os Ye'kuana de Auaris faziam viagens que percorriam grandes extensões, passando por vários rios e ultrapassando as fronteiras nacionais.

Nas últimas décadas desse século, especificamente nos anos 80, a relação dos Ye'kuana com a cidade de Boa Vista foi intensificada, inclusive com muitos jovens que foram estudar o ensino médio nas escolas da capital; buscavam, nesse mesmo período, estabelecer uma rede de trocas com os proprietários e moradores das fazendas do rio Uraricoera e "a capital do estado tornou-se o centro das operações, principalmente com o boom do garimpo e o aumento dos serviços prestados à saúde indígena" (MOREIRA, 2007, p. 77).

Os Ye'kuana chegaram a Auaris em 1960, como ponto final de uma trajetória que teve início por volta de 1880, saindo da comunidade ljekudeinha, chegando onde está hoje a pista na região de Auaris, num período de aproximadamente 80 anos. Segundo os moradores mais antigos de Fuduwaadunha, infelizmente hoje as comunidades não se deslocam mais da mesma forma que antes, uma vez que a sedentarização observada na região (no lado brasileiro) é decorrente do modelo de atendimento à saúde indígena implantado na região, que construiu um único polo-base (organização espacial do atendimento à saúde indígena) e impactou as dinâmicas de ocupação do espaço das populações indígenas, como é o caso das roças que diminuíram sua produção decorrente do intensivo uso do solo, que já é pouco fértil, com redução do rodízio das áreas de roças. 


\section{A elaboração do calendário socionatural e mapas}

A construção do calendário serviu para análise de uso do território e para indicar em mapas as atividades destacadas pela comunidade. O calendário socionatural é uma proposta teórico-metodológica desenvolvida por Gasché e Vella (2010) que, a partir do Método Indutivo Intercultural/MII, realiza um levantamento de informações. Tem como suporte a interação sociedade-natureza, identificada através das atividades humanas, e o calendário socionatural que tem a função de sistematizar as informações sobre as atividades sociais de uma determinada comunidade ao longo de um ano (REPETTO; BETHONICO, 2019). O calendário socionatural permite um levantamento das atividades desenvolvidas por uma comunidade, relacionando-as a indicadores ambientais (animais, vegetais, astronômicos, climáticos) que servem de referência temporal para ocorrências mensais no período de um ano; permite visualizar as formas de uso do espaço geográfico e das interações que se estabelecem entre o homem e a natureza. Tem sua base na teoria da atividade e esta

nos orienta a compreender o desenvolvimento humano e expressa em ações de transformação de natureza. Podemos pensar as 'atividades humanas' com categorias de análise para compreender este complexo processo de apropriação de mundo, por meio delas se transforma a natureza e a cultura se manifesta. (REPETTO; CARVALHO, 2015, p. 52)

Para construir o calendário foi necessária uma reunião na comunidade que ocorreu em dois dias. Os participantes foram indicados pela liderança, sendo três sábios (homens), um agente indígena de saúde (homem) e três professores (homens). No momento, não foi possível contar com a participação de mais pessoas, pois a comunidade estava ocupada com outras atividades, como a construção da casa redonda Ättä (casa comunitária).

Antes do início da oficina, foi esclarecido aos participantes sobre o encontro e os objetivos da pesquisa, quando concordaram de forma voluntária com a participação. As informações sobre as atividades foram organizadas em um quadro com colunas para cada mês do ano e, em seguida apontaram os indicadores (astronomia, clima, animais, 
vegetais, problemas ambientais e saúde). Ocorriam discussões e conversas entre eles, mas entre todos os participantes, o senhor Pery Magalhães era quem se destacava; é a liderança mais velha da comunidade. As outras pessoas também ajudavam e Pery fazia perguntas aos presentes, para tirar dúvidas. Na verdade, foi um tipo de conversa entre eles.

Moradores foram entrevistados para relatarem sobre as mudanças que percebiam no momento após o contato com os não indígenas, os pontos positivos e negativos dessas mudanças e quais problemas a comunidade enfrenta atualmente. Esse momento foi, também, para saber os lugares de caça, de pesca, de coleta de palha e madeira para construção das coberturas das casas. Foram entrevistadas pessoas de acordo com o conhecimento que têm e a sua idade (mais velhos) que identificaram os locais de uso através de referências geográficas, como serras, rios e igarapés. Os locais foram georreferenciados para construção de mapas no programa QuantumGis de geoprocessamento, utilizando como base a rede de drenagem e limites territoriais nacionais.

\section{Atividade da comunidade Fuduwaadunha}

Na década de 1970, os Ye'kuana (ou Maiongong) e os Sanumã ocupavam áreas contíguas e a população era de 200 habitantes, somando os dois povos (Ramos, 1990). Atualmente, a região de Auaris apresenta um crescimento no número de comunidades e população, apontando para mudanças no padrão de ocupação da área do entorno da comunidade Fuduwaadunha (Quadro 1).

Quadro 1 - População aproximada e número de aldeias de Auaris

\begin{tabular}{|c|c|c|c|c|c|}
\hline Ano & $\begin{array}{c}\text { População } \\
\text { Sanumã }\end{array}$ & $\begin{array}{c}\text { População } \\
\text { Ye'kuana }\end{array}$ & Total & $\begin{array}{c}\mathbf{N}^{\circ} \text { de } \\
\text { Aldeias }\end{array}$ & Fonte \\
\hline 1974 & 296 & 60 & 384 & 9 & Ramos, 1991 \\
\hline 1991 & 430 & 160 & 590 & 16 & Ramos, 1991 \\
\hline
\end{tabular}




\begin{tabular}{|c|c|c|c|c|c|}
\hline 2004 & 1495 & 295 & 1.730 & 31 & URIHI, 2004 \\
\hline 2007 & 2014 & 314 & 2.328 & 27 & $\begin{array}{c}\text { FUNASA, } \\
2007\end{array}$ \\
\hline 2011 & 2426 & 379 & 2.805 & 32 & SESAI, 2011 \\
\hline 2015 & 2690 & 427 & 3.117 & 36 & SESAI, 2015 \\
\hline
\end{tabular}

Fonte: Organização dos autores, 2021.

Destaca-se o crescimento demográfico dos Sanumã nos últimos anos, considerando que das 32 aldeias identificadas em 2011 pela Secretaria Especial de Saúde Indígena (SESAI) na região de Auaris, apenas 04 são Ye'kuana. Mesmo considerando as diferentes fontes de informações, o quadro nos permite tirar algumas conclusões: I) a região de Auaris apresentou um crescimento populacional de $731 \%$ no período de 37 anos; II) este crescimento foi mais intenso entre os Sanumã (819,6\%), sendo que os Ye'kuana também apresentaram um elevado crescimento (631,67\%), levando em consideração os processos migratórios que marcam a história recente dos dois povos; III) além do aumento do número de aldeias neste período (de 09 para 36), observa-se uma ampliação da média de moradores por aldeia, quando em 1974 existiam cerca de 43 habitantes por aldeia e, em 2011, este número eleva-se para 88 , indicando não apenas um aumento populacional, mas uma concentração de pessoas em um mesmo espaço, pressionando, dessa forma, os recursos naturais disponíveis. Essa situação é geradora de conflitos ambientais, uma vez que os espaços de caça, pesca e roça estão com o uso mais intenso podendo gerar seu esgotamento.

A mobilidade espacial que caracterizou o antigo modo de ocupação indígena foi um fator importante para garantir a sustentabilidade ao longo da história; quando uma comunidade identificava a escassez de um recurso natural, ocorria a mudança de parte ou todos os moradores para áreas mais fartas. Atualmente, presenciamos a sedentarização das comunidades. Segundo os moradores, a comunidade Fuduwaadunha mudou três vezes de lugar, mas a distância não foi maior que um ou dois quilômetros, ou seja, apenas mudaram o local de suas casas, porque a comunidade continua retirando os recursos naturais dos mesmos lugares como zonas de caça, de pesca, áreas de roças, locais de 
retirada das palhas e das madeiras.

$\mathrm{Na}$ visão dos moradores, houve um "privilégio" de adquirir materiais industrializados por meio do contato com os missionários da MEVA e com as instituições governamentais que se instalaram em Auaris, como Exército e as pessoas que atuam na saúde indígena. Além disso, foram criadas as escolas indígenas através da Secretaria de Educação do Estado de Roraima. A inserção de material industrializado nas comunidades indígenas facilitou a vida das pessoas, como o uso de arma de fogo para a caça, machado, facão e rede de pesca. Muitos desses instrumentos facilitam as atividades e, para os moradores, são os principais causadores de escassez de caça e dos peixes em Auaris. Nessa região não há peixes maiores, pois o rio Auaris é bastante acidentado e com cachoeiras e, por isso, os peixes maiores não conseguem subi-lo. Não existe um controle da pesca na época de desova de peixes e, neste período, muitas famílias aproveitam para usar a rede de pesca e o timbó, vegetal que possui uma toxina que afeta a respiração dos peixes. A redução da caça nas áreas de mata próximas às comunidades é expressa no momento em que afirmam que caminham longas distâncias que podem chegar a dois dias ou mais para buscar caça.

Hoje em dia, enfrentam a situação de solos com exaustão de nutrientes, porque as áreas de roças foram usadas várias vezes. As terras boas para o cultivo estão ficando cada vez mais distantes das comunidades; muitas vezes os pais de famílias estão utilizando as capoeiras novas e assim não esperam o tempo necessário para a regeneração completa da área (pelo menos 10 anos). Alguns terrenos já estão degradados e no lugar do mato estão as samambaias, como informam os moradores.

De acordo com o relatório da consultoria no âmbito do projeto Yanomami, feito em 2012, foram encontrados problemas com as culturas de mandioca e banana, decorrentes do adensamento e do uso prolongado das áreas de roça, fatores que contribuem para o aumento da população de insetos e microrganismos danosos para as culturas agrícolas. O plantio consecutivo de uma mesma espécie favorece o estabelecimento das doenças por meio do aumento de seus inóculos, como é o caso do cultivo da mandioca e macaxeira. O mesmo relatório informou a presença de pragas nas roças cultivadas nas comunidades Sanumã e Ye’kuana (SILVA, 2014). 
A roça, a caça, a pesca, festividades e reuniões são atividades dos Ye'kuana que vivem em Fuduwaadunha. Expressam a interação sociedade e natureza e a forma como a vida se desenvolve. Um dos resultados da pesquisa foi o levantamento dessas atividades, demonstradas no calendário socionatural (Quadro 2).

Quadro 2 - Calendário socionatural da comunidade Fuduwaadunha

\begin{tabular}{|c|c|c|c|}
\hline Período & Atividades & Indicadores & Quem realiza \\
\hline Janeiro & $\begin{array}{l}\text { - pesca com timbó; } \\
\text { - caça; } \\
\text { - férias escolares; } \\
\text { - caçadas longas. }\end{array}$ & $\begin{array}{l}\text { - algumas constelações ou estrelas } \\
\text { como Plêiades e Escorpião; } \\
\text { - clima é muito frio durante o dia e à } \\
\text { noite; } \\
\text { - rios e igarapés secos (verão); } \\
\text { - mutum e jacu (esses pássaros } \\
\text { cantam); as aves estão com “ovos } \\
\text { na barriga”; } \\
\text { - época das cigarras; } \\
\text { - doenças aparecem como } \\
\text { furúnculos, abcessos, tumores, } \\
\text { terçol, febres entre outras. }\end{array}$ & $\begin{array}{l}\text { - os homens e } \\
\text { meninos vão } \\
\text { buscar o timbó, } \\
\text { enquanto as } \\
\text { mulheres e as } \\
\text { meninas } \\
\text { trabalham com } \\
\text { timbó cultivado } \\
\text { que estão nas } \\
\text { roças ou nos } \\
\text { quintais da } \\
\text { comunidade; } \\
\text { - as famílias saem } \\
\text { para caçar à } \\
\text { noite; }\end{array}$ \\
\hline Fevereiro & $\begin{array}{l}\text { - queimar as roças; } \\
\text { - pescaria com timbó; } \\
\text { - caçadas durante a } \\
\text { noite } \\
\text { - catar lagartas. }\end{array}$ & $\begin{array}{l}\text { - igarapés secos; estiagem forte; } \\
\text { - o clima muito quente no período do } \\
\text { dia e à noite, frio; } \\
\text { - canto do mutum e de outras aves; } \\
\text { as aves estão com ninhos; } \\
\text { - temos as lagartas comestíveis } \\
\text { (Masoiya estão em larvas); } \\
\text { - as antas estão no rio; } \\
\text { - começa a floração de bacaba. }\end{array}$ & - as famílias. \\
\hline Março & $\begin{array}{l}\text { - começar a tirar as } \\
\text { mudas de banana, } \\
\text { manivas e outras } \\
\text { que serão plantadas } \\
\text { nas roças novas; } \\
\text { - realizar o ritual para } \\
\text { espantar espíritos } \\
\text { ruins das roças; }\end{array}$ & $\begin{array}{l}\text { - clima quente (dia) e frio (noite); } \\
\text { - canto das rãs; } \\
\text { - os peixes botam ovos (que não } \\
\text { sobrevivem); } \\
\text { - floração de muitas frutas. }\end{array}$ & $\begin{array}{l}\text { - tirar as manivas } \\
\text { é atividade das } \\
\text { mulheres, mas } \\
\text { os homens } \\
\text { podem ajudar a } \\
\text { carregar para a } \\
\text { roça. }\end{array}$ \\
\hline
\end{tabular}




\begin{tabular}{|c|c|c|c|}
\hline & $\begin{array}{l}\text { - escolher madeiras } \\
\text { para construção de } \\
\text { casas; } \\
\text { - caçar rãs. }\end{array}$ & & \\
\hline Abril & $\begin{array}{l}\text { - tempo de começar a } \\
\text { construção de casa } \\
\text { como ättä, } \\
\text { - primeira colheita } \\
\text { das roças novas; } \\
\text { - caça e pescam com } \\
\text { timbó; } \\
\text { - caçar com os } \\
\text { cachorros, } \\
\text { - doenças por causa } \\
\text { das primeiras } \\
\text { chuvas. }\end{array}$ & $\begin{array}{l}\text { - primeiras chuvas; } \\
\text { - época do veado e anta; } \\
\text { - canto do mutum; } \\
\text { - os filhotes das aves começam a } \\
\text { voar; } \\
\text { - desova das rãs; } \\
\text { - frutas maduras. }\end{array}$ & $\begin{array}{l}\text { - a colheita na } \\
\text { roça é uma } \\
\text { atividade de } \\
\text { toda a } \\
\text { comunidade; } \\
\text { - os homens } \\
\text { caçam ou } \\
\text { pescam com } \\
\text { timbó. }\end{array}$ \\
\hline Maio & $\begin{array}{l}\text { - construção de casas; } \\
\text { - caça com cachorro; } \\
\text { - colheita nas roças } \\
\text { novas; } \\
\text { - retirar plantas } \\
\text { daninhas das roças. }\end{array}$ & $\begin{array}{l}\text { - os igarapés estão cheios; } \\
\text { - chuvas e enchentes; } \\
\text { - frutas maduras que alimentam as } \\
\text { aves; } \\
\text { - os cupins, saúvas e sedis estão } \\
\text { voando. }\end{array}$ & $\begin{array}{l}\text { - as mulheres } \\
\text { cuidam da roça. }\end{array}$ \\
\hline Junho & $\begin{array}{l}\text { - fazer roças de } \\
\text { capoeira. }\end{array}$ & $\begin{array}{l}\text { - muita chuva, chamado Konoojo } \\
\text { annadö; } \\
\text { - igarapés com água barrenta (sujos); } \\
\text { - canto de filhotes de passarinho } \\
\text { se’sekaadö; } \\
\text { - início da época de minhocuçus; } \\
\text { - renovação de folhas de algumas } \\
\text { árvores. }\end{array}$ & - a família. \\
\hline Julho & $\begin{array}{l}\text { - fazer roça; } \\
\text { - caçar quando não } \\
\text { chove; } \\
\text { - caçar minhocuçu; }\end{array}$ & $\begin{array}{l}\text { - chuvas; } \\
\text { - igarapés cheios e sujos; } \\
\text { - renovação das folhas das árvores; } \\
\text { - minhocuçu; } \\
\text { - Os besouros cortam os galhos das } \\
\text { árvores; } \\
\text { - aparecem as doenças como diarreia. }\end{array}$ & - a família. \\
\hline Agosto & $\begin{array}{l}\text { - escolher o lugar } \\
\text { para fazer a roça; }\end{array}$ & $\begin{array}{l}\text { - a chuva começa a diminuir; } \\
\text { - rios cheios; no final do mês } \\
\text { começam a baixar; } \\
\text { - o minhocuçu fica em período fértil; } \\
\text { - floração de árvores. }\end{array}$ & $\begin{array}{l}\text { - os homens } \\
\text { escolhem os } \\
\text { locais das roças. }\end{array}$ \\
\hline Setembro & - fazer roças de mata & - pouca chuva; & - homens; \\
\hline
\end{tabular}




\begin{tabular}{|c|c|c|c|}
\hline & $\begin{array}{l}\text { primária; } \\
\text { - caçar com o } \\
\text { cachorro; } \\
\text { - caçar passarinhos } \\
\text { com sarabatana; } \\
\text { - pescarias com timbó } \\
\text { e anzol. }\end{array}$ & $\begin{array}{l}\text { - os igarapés estão secando (baixos); } \\
\text { - frutas maduras que servem de } \\
\text { alimentos para os pássaros. }\end{array}$ & $\begin{array}{l}\text { - jovens caçam } \\
\text { passarinhos. }\end{array}$ \\
\hline Outubro & $\begin{array}{l}\text { - fazer roças em } \\
\text { matas primárias; } \\
\text { - caçar com os } \\
\text { cachorros. }\end{array}$ & $\begin{array}{l}\text { - verão; } \\
\text { - renovação das cascas das cigarras; } \\
\text { - início do canto do mutum; } \\
\text { - as folhas das árvores estão } \\
\text { renovadas. }\end{array}$ & $\begin{array}{l}\text { - família; } \\
\text { - os homens } \\
\text { caçam. }\end{array}$ \\
\hline Novembro & $\begin{array}{l}\text { - fazer viagens para } \\
\text { outras comunidades; } \\
\text { - festas de roça; } \\
\text { - atividades } \\
\text { particulares } \\
\text { (artesanato, cordas, } \\
\text { cestos, peneiras, } \\
\text { balaios). }\end{array}$ & $\begin{array}{l}\text { - fim das chuvas; } \\
\text { - o japim fazer ninho; } \\
\text { - floração de árvores; } \\
\text { - aparecem as doenças de verão } \\
\text { como abcesso, tumor, terçol, feridas } \\
\text { inflamadas, feridas com pus. }\end{array}$ & $\begin{array}{l}\text { - a família } \\
\text { - a comunidade } \\
\text { festeja. }\end{array}$ \\
\hline Dezembro & $\begin{array}{l}\text { - atividades } \\
\text { particulares. }\end{array}$ & $\begin{array}{l}\text { - início do verão; } \\
\text { - frutas maduras; } \\
\text { - as aves estão chocando os ovos; } \\
\text { - doenças do verão: abcesso, tumor, } \\
\text { terçol, feridas inflamadas, feridas } \\
\text { com pus. }\end{array}$ & $\begin{array}{l}\text { - membros da } \\
\text { família. }\end{array}$ \\
\hline
\end{tabular}

Fonte: moradores da comunidade Fuduwaadunha. Organização dos autores, 2021.

As atividades de subsistência têm destaque no calendário socionatural da comunidade Fuduwaadunha. A roça, a caça e a pesca são destacadas durante todo o ano, variando a técnica de acordo com as condições climáticas. O calendário socionatural é expresso, também, na forma gráfica (Figura 2). 
Figura 2 - Calendário Socionatural da comunidade Fuduwaadunha

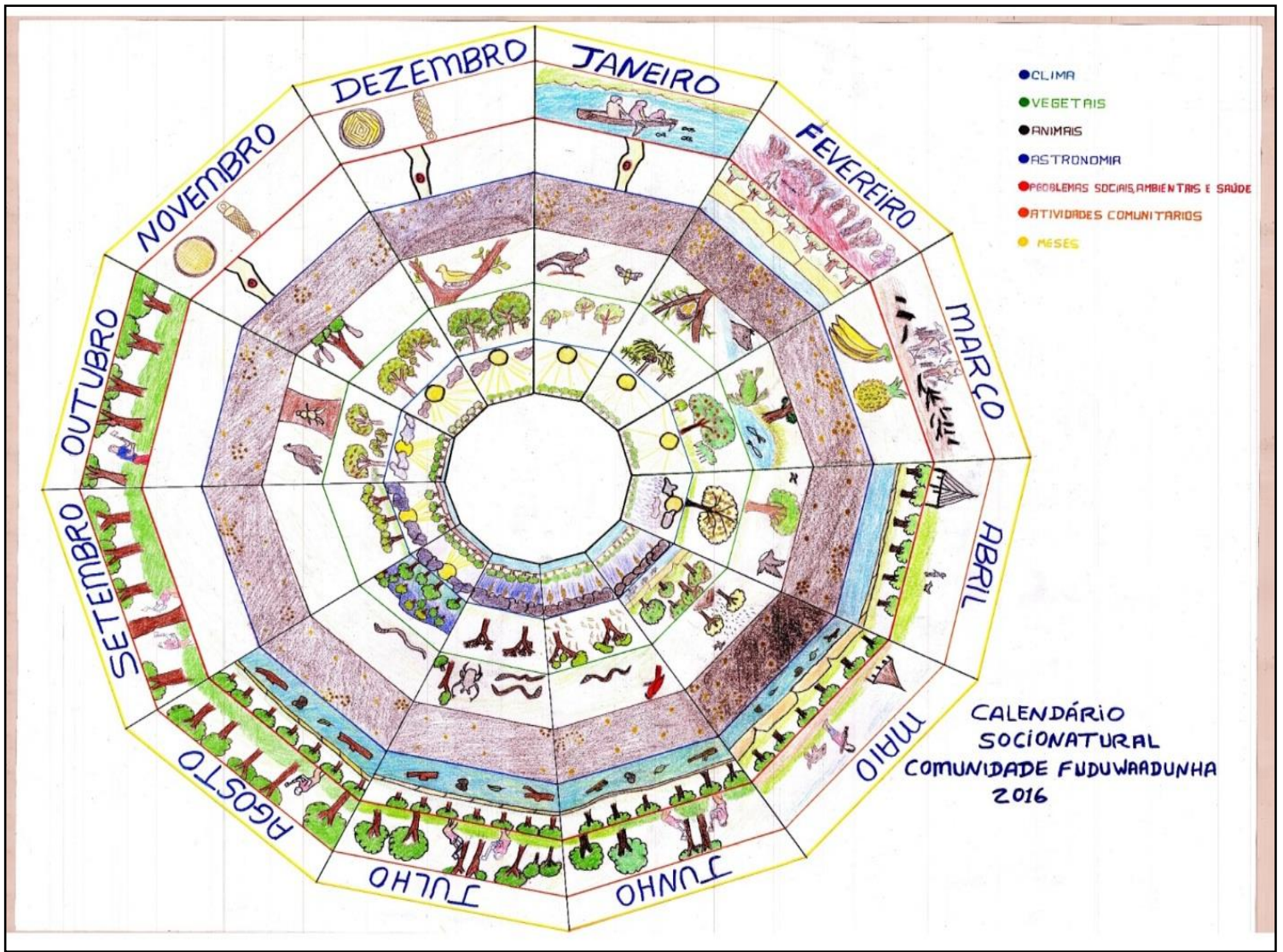

Fonte: moradores da comunidade Fuduwaadunha. Organização dos autores, 2021.

Uma roça merece vários cuidados por parte da família. No mês de agosto, os pais de família escolhem o lugar para fazer a roça que, neste período do ano, é feita nas áreas de mata virgem. $O$ indicador animal estabelece algumas regras: o besouro que na língua Ye'kuana chamam de dakäänä, corta os galhos das árvores e no conhecimento indígena é muito importante, pois ele dá o sinal de que é a hora de fazer roças e, para os Ye'kuana, ele está fazendo roça dele. Não se pode fazer roça em mata virgem antes de dakäänä dar o sinal, é preciso esperar; se for feita antes, os trabalhadores podem se acidentar. Por isso, é importante esse conhecimento que deve passar para a nova geração.

Os meses de setembro e outubro são dedicados aos plantios e cultivos nessas novas roças, porém, antes de iniciar o trabalho na roça nova, o (a) sábio (a) achudi eyaajä 
faz um ritual para espantar os espíritos ruins que podem prejudicar a plantação e precisa pedir autorização aos donos do lugar (em língua Ye'kuana ewansokaadö). Os moradores destacaram que as roças são individuais ou coletivas e uma família pode convidar outros moradores para as atividades deauddajä shakaichadö (fazer buraco no solo) e aichädö (colocar a muda de maniva no buraco). Se o dono da roça decidir convidar, ele precisa caçar dias antes como contrapartida de servir alimentos para os ajudantes. Existe uma divisão neste ritual, sendo que o homem convida os homens da comunidade, e a mulher convida as mulheres. Quando a comunidade é convidada, todos participam: adultos, jovens e as crianças de ambos os sexos. As mulheres levam Yadaaki (bebida tradicional fermentada), exceto as mulheres que estão menstruadas.

No mês de abril ocorre a primeira colheita nas roças novas, atividade que se estende até maio e é realizada principalmente pelas mulheres e crianças. Outra opção para locais de roças são as capoeiras, sendo o mês de junho o mais indicado e, com essas duas modalidades, a agricultura é praticada durante todo o ano, com algumas dificuldades como a quantidade de plantas daninhas, conferindo muito trabalho para as mulheres, pois crescem rápido e dão mais trabalho, além da chuva que prejudica os trabalhos na roça.

A caça é realizada pelos homens ou, em algumas situações, por parte da família. Normalmente, saem para caçar no período da noite e no mês de janeiro fazem as caçadas longas, que chegam a durar de 10 a 15 dias. Nos meses de abril e maio, usam o cachorro como apoio nas caçadas, principalmente quando os alvos são veados e antas, porque já começa a chover e, depois da chuva, os cães auxiliam a seguir o rastejo do animal. $O$ minhocuçu (minhoca grande) é apreciado para caça e observam o desenvolvimento deste animal que começa a aparecer no mês de junho, período de muita chuva (Konoojo annadö). A caça do minhocuçu ocorre no mês de julho, atividade comum a todos os moradores da região (Ye'kuana e Sanumã); eles observam os ciclos dos animais e registram que no mês de agosto os minhocuçus ficam em período fértil.

Outros animais são caçados nos momentos de estiagem como as rãs. O mês de março é o tempo de canto de vários tipos de rãs e os moradores caçam esses animais que recebem os nomes de komjakä, kudaadai, wadeeke, wa'wa, shinhaawe e fu'juku; neste 
mesmo mês, apontam que os peixes botam seus ovos, porém estes não sobrevivem por causa da seca e as formigas os comem. Segundo os moradores, para comer pela primeira vez no ano, deve haver o töyachuuma (canto de cura) para as rãs, as lagartas e frutas. 0 mutum é uma ave apreciada e identificam seu período pelo canto que começa no mês de janeiro e se prolongam até abril, quando os filhotes de várias aves começam a voar.

A pesca é frequente, com redução no período das cheias (inverno) como no mês de julho, momento de muitas chuvas e quando os rios ficam cheios, a pesca se torna muito difícil nessa época. Utilizam como técnicas o timbó e o anzol; o mês de setembro tem destaque por não haver chuvas, o que permite pescaria com timbó pois os igarapés baixaram e, também, a pescaria com o anzol.

A pesca e a caça têm relação com o ciclo das plantas e, segundo os moradores, no mês de março ocorre a floração de frutas comestíveis como wöda, sadajui, waju'näämä, kudikudi, wakaadu e odoi e, em maio, a disponibilidade de frutas das árvores shakuudu, täjö’seemö, wadaatani, ma'wiyu, änkutu, kuweedu que servem de alimento para as aves; destacaram que as frutas de árvores como emmadi e kuyuuwiyu (árvore de mata nativa) estão maduras e muitos passarinhos comem essas frutas; nessa época, as pessoas caçam os passarinhos com sarabatana. Agosto é época de floração de árvores como ajiicha e, quando essa árvore fica com flor, anuncia muitos trovões e raios. Outras árvores também florescem, como kuyuwiyu e emmadi. No fim de ano, novembro e dezembro, ocorre a floração das árvores dejooko, kadiimani e entre outras que frutificam no mês de dezembro.

Provavelmente, os Ye’kuana têm mais tempo de atividades agrícolas em comparação com seus vizinhos Sanumã e, como afirma Ramos (1980, p. 26), "as roças Maiongong são maiores e mais sortidas que os Sanumã. Este fato parece dever-se a uma tradição longa que tem os Maiongong no desempenho de atividade agrícolas". Enquanto seus vizinhos Sanumã, provavelmente, desenvolveram a atividade agrícola há menos tempo, porque esse povo tem tradição de coletar e caçar; eles são caçadores por excelência.

Esses povos dependem de caça e pesca. A partir dessas atividades, retiram o 
sustento da família inteira, às vezes da comunidade inteira. Quando alguém caça ou pesca, o produto da atividade é repartido pelos membros da família ou até de toda comunidade; depende da caça, se for grande, toda comunidade é beneficiada. Antes da chegada do não indígena na região de Auarís, os Ye'kuana tinham poucas armas de fogo. Como eles são considerados viajantes pelos rios amazônicos e do rio Orinoco, na Venezuela, também são considerados comerciantes e, através do comércio conseguiam ferramentas como machado, terçado, munição e armas (MELLATI, 2009). A chegada dos missionários facilitou a vida dos povos que ali habitam, desta vez não só os Ye'kuana, mas também os Sanumã começaram se beneficiar adquirindo as armas de fogo, munições, ferramentas para pesca, machado e terçados que são bem cobiçados pelos indígenas.

Os moradores mais antigos contam que, antes da chegada dos missionários, havia muita caça e pesca. Com a espingarda, passaram a ter maior precisão em acertar o alvo; facilitou-se a caça de aves e dos animais de médio porte como paca, veado entre outros. De acordo com as informações dos entrevistados, as áreas de caça são próximas aos cursos de água, como o rio Caura, e para essa atividade ultrapassam a fronteira nacional.

A caça começou a diminuir cada vez mais e a população aumentava; algumas comunidades começaram a se aproximar, atraídas pelos materiais manufaturados trazidos pelos não indígenas e, com isso, cada vez mais ampliou-se a pressão sobre recursos naturais, principalmente animais e peixes. A caça e pesca ficaram, além de mais difíceis, mais distantes, chegando a caminhadas de um a três dias, atravessando a fronteira Brasil/Venezuela em direção leste, oeste e norte da região.

Na comunidade Fuduwaadunha, os Ye'kuana proíbem alguns lugares de caça para os Sanumã. Existem dois lugares nessa situação: um está no rio Auaris; começa a partir de cachoeira de Caranguejo e vai até a nascente do rio. Esse lugar é respeitado pelos Sanumã que não passam a cachoeira Caranguejo. Em entrevista, o senhor Pery informou que tiveram reunião com os Sanumã no ano 1970, quando ficou definido que eles, os Sanumã, não poderiam passear por lá, porque havia uma comunidade que não tinha atendimento de saúde, a atual comunidade Pedra Branca. Justificaram pelo fato de que os Sanumã poderiam levar doenças para essas pessoas e naquela comunidade havia um senhor já em idade avançada; qualquer doença poderia levá-lo à morte. Assim foi feito o acordo e, até 
hoje não há presença de Sanumã naquela parte do território. Atualmente, a região busca organizar as atividades de acordo com as necessidades dos moradores (Figura 3).

Figura 3 - Mapa da região de Auaris - uso do território pelos Sanumã e Ye'kuana (2017)

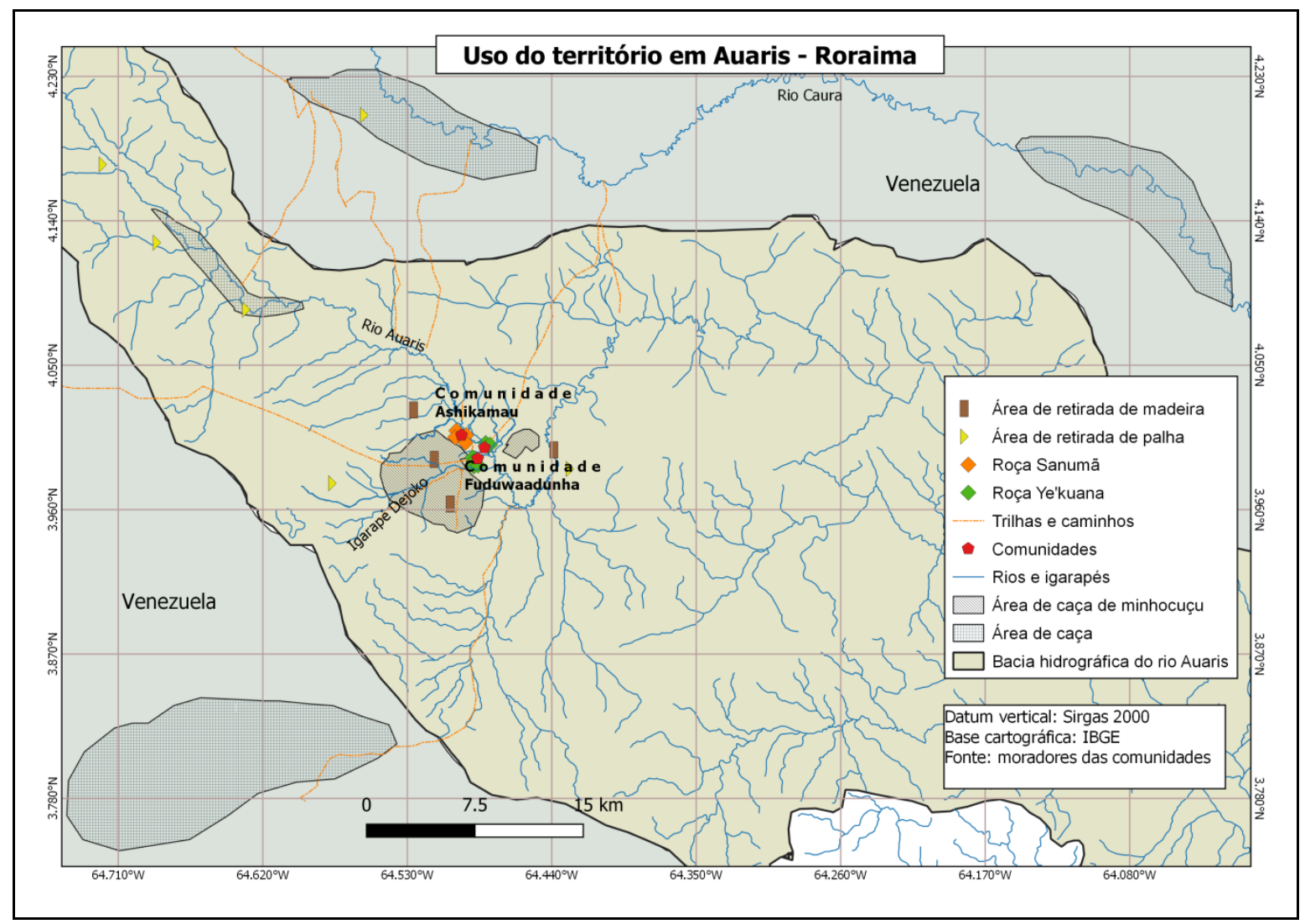

Fonte: moradores da comunidade Fuduwaadunha. Organização dos autores, 2021.

Existe um poder atuando sobre o território de domínio e os Ye'kuana delimitam as áreas de controle e constroem estratégias para impedir que os Sanumã acessem ou utilizem os recursos desses espaços. Os moradores mais antigos da comunidade Fuduwaadunha relatam que no início (anos 1950/1960) havia muita bacaba e açaí. Essas duas espécies foram muito utilizadas por moradores para fazer as coberturas de casas. Nos anos 1960, os Ye'kuana construíram a casa ättä (casa redonda), coberta por palha de açaí. Na década de 1970, construíram uma casa comunal, onde quase toda comunidade morava; esta casa era enorme e foi coberta por palha de bacabeira. Por volta de 1980, os Ye'kuana mudam sua estratégia e começam a fazer suas casas cobertas de cavaco de 
cedro; esta utilização foi até final de 1999. Nessa mudança de estratégia, muitos cedros foram derrubados. Esse material durava mais tempo, entre 15 e 20 anos; já a palha dura menos tempo, entre cinco e oito anos.

Com a mudança socioeconômica junto aos Ye'kuana, a inserção do trabalho renumerado de alguns moradores da comunidade Fuduwaadunha a partir ano 2000, tem início a construção de casas com as telhas de zinco ou alumínio, compradas na cidade de Boa Vista/RR ou de Manaus/AM. Atualmente, quase todas as casas da comunidade são cobertas por telhas de zinco ou alumínio, cuja durabilidade dos materiais é valorizada pelos moradores.

No ano de 2015, a comunidade Fuduwaadunha construiu uma casa tradicional ättä e para conseguir palha para a cobertura, precisaram caminhar 12 horas até a Venezuela e subir o rio Auaris por dois dias de viagem com motor de popa e muita cachoeira. Além do tempo de barco, precisaram de mais 12 horas de caminhada para puxarem a palha; levaram quatro dias para chegar à comunidade. Todos os moradores se envolveram nesta atividade, e também as comunidades Sanumã Katana e Momoipu colaboraram com os Ye'kuana. A extração de madeira é um processo longo e tem início no mês de março com a escolha das árvores. Os meses de abril e maio são destinados à derrubada, transporte e construção. As comunidades da região retiram muitas madeiras, como cedros e estas, como os demais recursos do extrativismo, estão cada vez mais distantes da comunidade. A derrubada da floresta para fazer a roça contribuiu para esse distanciamento; muitas madeiras são derrubadas e não são aproveitadas pelos moradores.

\section{As fragilidades nos limites territoriais}

Os povos indígenas vivem de modo diferente; as moradias ocupam o mesmo espaço por vários anos, principalmente naquelas comunidades onde há a presença de missões religiosas. Na Terra Indígena Yanomami, as missões se instalaram nos anos 1950 e 1960 e, desde essa chegada, algumas comunidades permanecem ocupando os mesmos locais, como é caso da área de estudo, com convivência de dois grupos em um mesmo espaço geográfico há vários anos, em torno de cinco gerações. Desde os primeiros 
contatos entre os dois povos aconteceram hostilidades, até alguns casos de morte; os dois povos "não se dão bem um com o outro", como relatam os moradores. Os Ye'kuana, segundo os depoimentos dos moradores, consideram a área como seu território tradicional e que foi "invadido" pelos Sanumã, que ocuparam seus lugares de caça, de pesca. Hoje, a comunidade Ye'kuana ficou no meio de várias comunidades Sanumã. A distância de Fuduwaadunha para a comunidade Sanumã Ashikamau é de um quilômetro e meio, sendo possível observar a área sob o domínio dos Ye'kuana e quando os Sanumã caçam ou fazem uma roça há reclamação por parte dos Ye'kuana no sentido de perceberem uma "invasão" de território (Figura 4).

Figura 4 - Mapa de área limites de fragilidades territoriais

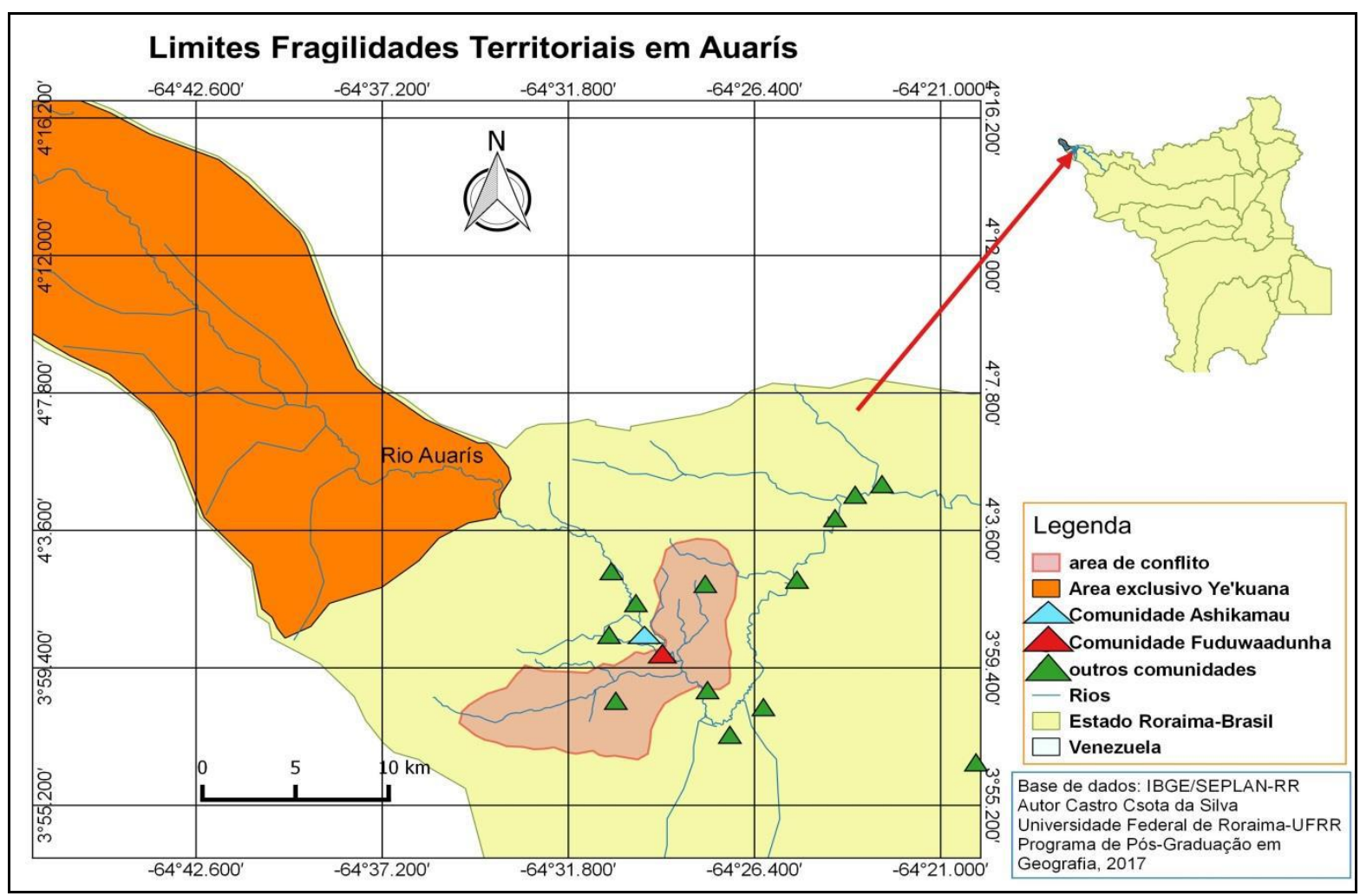

Fonte: moradores da comunidade Fuduwaadunha. Organização dos autores, 2021.

Nas áreas denominadas como de fragilidades territoriais ocorrem constantes conflitos entre as comunidades próximas, principalmente as queixas por parte dos Ye'kuana sobre roubos de roças e de canoas, que são as principais reclamações. 
Ocorreram vários encontros entre as lideranças das duas comunidades que fazem acordos, mas estes são quebrados rapidamente pelas pessoas. Isso ocorre devido ao tuxaua (liderança local) não ter poder de punir as pessoas que quebram o acordo e as situações acabam sem nenhuma solução, segundo os depoimentos coletados.

No início, não houve planejamento para ocupação do território pelas comunidades, tanto Ye'kuana, quanto Sanumã, e as pessoas ainda o fazem onde acham melhor; assim aconteceu em Auaris, e os moradores acreditam que não houve respeito de limites. Para os entrevistados, as duas comunidades não poderiam ocupar uma distância menor do que dois quilômetros e precisavam delimitar os locais de caça e de pesca, como uma forma de controle e gestão do território e de seus recursos. Da forma como a área foi ocupada, as comunidades da região de Auaris não têm como se sustentar por vários anos no mesmo lugar, porque esses povos sobrevivem dos recursos naturais. A pressão é muito grande sobre os recursos naturais, diferente das comunidades indígenas que estão próximas das cidades, e que na maioria das vezes buscam alimentos nos supermercados da cidade, o que não é o caso aqui apresentado.

\section{Considerações finais}

As pressões humanas sobre os recursos naturais são inevitáveis. Imagens de satélites mostram que as terras indígenas são, em sua maioria, preservadas e no seu entorno já não possuem mais a floresta. Os indígenas e suas comunidades pouco alteram o seu meio ambiente e retiram para sua subsistência somente aquilo que necessitam, mas o contato com a sociedade envolvente está mudando o cotidiano das famílias e a ocupação de seus territórios. Este é o caso da região de Auaris.

Para os Ye’kuana, o território é composto por elementos naturais, pelas produções humanas e pelos seres visíveis e invisíveis. As mudanças nos padrões de ocupação espacial, a pressão sobre os recursos naturais e usos intensos das áreas são consequências de um crescimento populacional. Comunidades que se estenderam espacialmente nas áreas de floresta apontam para problemas de gestão, preocupam os moradores que traduzem uma situação de interação com uma sociedade não índia e que 
oferece produtos manufaturados. Esses produtos alteraram a dinâmica da caça e da pesca, do uso de demais recursos naturais que, se por um lado aliviam a pressão sobre a natureza (caso da cobertura das casas), por outro intensificam a caça e a pesca (rede e espingarda).

Existe uma preocupação por parte das lideranças locais, tanto Ye'kuana e quanto Sanumã, para solucionar situações internas como os "roubos" e usos de territórios. Assim, observa-se uma tentativa de controle com a proibição de uso de alguns espaços pelos Sanumã, visando preservar a caça e a pesca. Não foi observado um sucesso nessas ações de gestão, segundo os próprios moradores.

Os povos indígenas têm grandes desafios para gestão de seus territórios e, primeiramente, devemos começar a pensar nos locais onde há maior concentração de pessoas. No caso da região de Auaris, desde 2015 houve o início da conversa com as comunidades Sanumã para propor a mudança de algumas comunidades. Nesse projeto estão envolvidas instituições governamentais, não governamentais e organizações indígenas. As mudanças das comunidades poderão diminuir a pressão sobre recursos naturais.

Os Ye'kuana participam da elaboração do Plano de Gestão Territorial e Ambiental da Terra Indígena Yanomami, junto ao Instituto Socioambiental - ISA, em uma busca de soluções para os conflitos territoriais. Defendem que é preciso ter algum projeto voltado para minimizar os problemas que envolvem o sofrimento das comunidades Sanumã e Ye'kuana, principalmente, aquelas comunidades que estão nas proximidades da pista.

\section{Referências}

GASCHÉ, Jorge; VELA, Napoleón. Sociedad bosquesina: ensayo de antropología rural amazónica, acompañado de una crítica y propuesta alternativa de proyectos de desarrollo. Iquitos: Instituto de Investigaciones de la Amazonia Peruana; Lima: CONCYTEC; Quioto: CIAS, v. 1, 2010.

GUIMARÃES, Silvia. O drama ritual da morte nos Sanumã. Tellus, Campo Grande: UCDB, n. 19, p. 111-128, jul./dez. 2010. 
MELATTI, Júlio Cezar. Maciço guianense ocidental retocado em 2009. Brasília, 2014. Disponível em:

https://www.google.com.br/?gfe_rd=cr\&ei=YqAYVJPgIMnB8gfT4ID4Aw\#q=MELATTI\%2C+ $\mathrm{J} \% \mathrm{C} 3 \%$ Balio+Cezar.+Maci\%C3\%A70+Guianense+Ocidental+Retocado+em+2009. Acesso em: 16 de abr. 2014.

MOREIRA, Elaine. Redes sociais e mobilidade espacial entre os Ye'kuana no Brasil. In: SOUSA, Cássio Noronha Inglez et al. (orgs.). Povos indígenas: projetos e desenvolvimento. Rio de Janeiro: Contra Capa Livraria, 2007. p. 75-95.

RAMOS, Alcida Rita. Memórias Sanumã: espaço e tempo em uma sociedade yanomami. São Paulo: Marco Zero: Ed.UnB, 1990.

RAMOS, Alcida Rita. Hierarquia e simbiose: relações intertribais no Brasil. São Paulo: HUCITEC, 1980.

REPETTO, Maxim; CARVALHO, Fabíola. Experiencias de investigación educativa intercultural en la formación de maestros indígenas en Roraima, Brasil. Desacatos, Ciudad de México, p. 50-65, mayo/ago. 2015. Traducción: Marcelo Reyes Aravena. Disponível em: http://www.scielo.org.mx/pdf/desacatos/n48/n48a4.pdf. Acesso em: 20 maio de 2017.

REPETTO, Maxim; BETHONICO, Maria Bárbara de Magalhães Calendários socionaturais: construção participativa de propostas educativas e de gestão territorial em comunidades indígenas de Roraima. Cadernos de Estudos Culturais, Campo Grande, v. 1, p. 87-103, jan./jun. 2019.

SARTORELLO, Stefano Claudio. Construir conocimientos escolares desde el territorio própio: el método inductivo intercultural en el modelo curricular de educación intercultural bilingüe de la unión de maestros de la nueva educación para México (UNEM) en Chiapas. In: PUIG, Andrés Fábregas (coord.). Chiapas: territorio, fronteras, migraciones, desarrollo: visiones interculturales multidisciplinarias. San Cristóbal de las Casas, Chiapas: Universidad Intercultural de Chiapas, 2011. p. 49-85.

SILVA, Castro Costa. Auaris e a história da ocupação: população, recursos naturais e território. 2014. Trabalho de Conclusão de Curso (Bacharelado em Gestão Territorial Indígena) - Instituto Insikiran de Formação Superior Indígena, Universidade Federal de Roraima, Boa Vista, 2014.

SILVA, Castro Costa; BETHONICO, Maria Bárbara de Magalhães. População indígena e saúde na região de Auaris: terra indígena Yanomami. Textos \& Debates, Boa Vista, n.18, p. 251-268, jan./jun. 2010. 
SILVA, Castro Costa; BETHONICO, Maria Bárbara de Magalhães. O conceito de território para o povo Ye'kuana que habita a região de Auaris: terra indígena Yanomami: Roraima. Revista de Estudos e Pesquisas sobre as Américas, Brasília, v. 3, n. 11, p. 159-176, 2017.

Recebido em: 30/11/2020 Aprovado em: 18/04/2021

Universidade do Estado de Santa Catarina - UDESC Centro de Ciências Humanas e da Educação - FAED

Volume 22 - Número 48 - Ano 2021 revistapercursos@gmail.com 